\title{
EVALUATION OF SURGICAL TREATMENT OF ROTATOR CUFF ANTEROSUPERIOR TEARS ARTHROSCOPICALLY
}

\author{
AVALIAÇÃO DO TRATAMENTO CIRÚRGICO DAS LESÕES \\ ANTEROSSUPERIORES DO MANGUITO ROTADOR \\ POR VIA ARTROSCÓPICA
}

\author{
Roberto Yukio Ikemoto ${ }^{1}$, luis Gustavo Prata Nascimento ${ }^{1}$, luiz Henrique Oliveira Almeida ${ }^{1}$, Rogerio Serpone Bueno ${ }^{2}$, \\ GUILHERMe HeNRIQUe VIEIRA LIMA², Joel MURACHOVSKY ${ }^{1}$ \\ 1. Hospital Ipiranga, São Paulo, SP, Brazil. \\ 2. Faculdade de Medicina do ABC, Santo André, SP, Brazil.
}

\section{ABSTRACT}

Objective: To evaluate the functional result of arthroscopic treatment in anterosuperior rotator cuff tears. Methods: Fifty-six patients submitted to arthroscopic repair of anterosuperior rotator cuff tears were evaluated. The follow-up time was five year and five months. All the tears were diagnosed by detailed physical and imaging examination. Statistical analysis was used to compare the preoperative and postoperative results of range of motion and the UCLA score, with Wilcoxon signed-rank test, 5\% significance level $(p \leq 0.05)$, the relationship between the subscapularis tear and postoperative results using the Mann-Whitney test, and between the pain length and the UCLA scale using Spearman's correlation. Results: A statistically significant improvement $(p<0.001)$ was found, comparing the range of motion and the UCLA preoperatively and postoperatively. $39 \%$ of the cases were classified as excellent, $33.9 \%$ as good, $23.7 \%$ as regular and $3.4 \%$ as bad results. A statistically significant relationship was found between the subscapularis tear type and the functional state, the pain length and the postoperative UCLA scale. Five complications, four reruptures and one adhesive capsulitis were found. Conclusions: The arthroscopic treatment for anterosuperior tears presented satisfactory results, with $8.5 \%$ of complications. Level of Evidence IV, Case series.

Keywords: Rotator cuff. Retrospective studies. Shoulder.
RESUMO

Objetivo: Avaliar o resultado funcional do tratamento artroscópico das lesões anterossuperiores do manguito rotado. Métodos: Avaliação de 59 pacientes com lesão anterossuperior submetidos a tratamento cirúrgico. O tempo de seguimento foi de 5,5 anos. As lesões foram diagnosticadas por exame físico e de imagem. A análise estatística comparou os resultados pré e pós-operatórios de amplitude de movimento e da escala da UCLA, com teste de pontos sinalizados de Wilcoxon, nível de significância de $5 \%(p \leq 0,05)$, a relação entre a lesão do subescapular e o pós-operatório pela aplicação do teste de Mann-Whitney, e entre o tempo de dor e a escala da UCLA pela correlação de Spearman. Resultados: Houve melhora estatisticamente significativa $(p<0,001)$ comparando-se a amplitude de movimento e a escala da UCLA nos períodos pré e pós-operatórios. 39\% dos casos foram classificados como excelentes resultados, 33,9\% bons, 23,7\% regulares e 3,4\% ruins. Houve relação estatisticamente significativa entre o tipo de lesão do subescapular e o resultado funcional, entre o tempo de dor e a escala da UCLA pós-operatória. Registramos cinco complicações, quatro re-rupturas e uma capsulite adesiva. Conclusão: O tratamento artroscópico das lesões anterossuperiores apresentou resultados satisfatórios, com 8,5\% de complicações. Nível de Evidência IV, Série de Casos.

Descritores: Manguito rotador. Estudos retrospectivos. Ombro.

Citation: Ikemoto RY, Nascimento LGP, Almeida LHO, Bueno RS, Lima GHV, Murachovsky J. Evaluation of surgical treatment of rotator cuff anterosuperior tears arthroscopically. Acta Ortop Bras. [online]. 2019;27(3):160-3. Available from URL: http://www.scielo.br/aob.

\section{INTRODUCTION}

Associated subscapular and supraspinal tendon tears are less frequent than other types of rotator cuff tears, such as posterior superior tears and isolated supraspinal tendon tears. Anterior superior tears usually have a worse prognosis than the above mentioned tears. Therefore, their treatment is a challenge for shoulder and elbow surgeries, and there is little national literature on this subject. ${ }^{1}$
With the advent of arthroscopy, partial subscapular tears are diagnosed with more precision than previously. ${ }^{2}$ Also, through arthroscopy, some tears that would require extensive surgical exposure can now be repaired by minimally invasive procedures. ${ }^{3}$ The objective of this study was to evaluate the clinical and functional outcome of arthroscopy of anterior superior rotator cuff tears.

All authors declare no potential conflict of interest related to this article.

This study was conducted at two institutions: FMABC and Hospital Ipiranga, São Paulo, SP, Brazil.

Correspondence: Luiz Henrique Luiz Henrique Oliveira Almeida. Avenida Tietê, 372, apto 81-b, Santo André, SP, Brazil. 09070-310. E-mail: Ihalmeida3@gmail.com 


\section{MATERIAL AND METHODS}

From August 2002 to February 2008, 1,056 shoulder arthroscopies were performed to repair rotator cuff tears, of which 59 (5.6\%) were performed to repair anterior superior tears. Thirty-nine patients were females and 20 were males aged 39 to 76 (mean of 57 years). The right side was the affected side in 45 patients $(76.27 \%)$ and the left side was the affected side in 14 patients (23.73\%). The dominant side was affected in 47 patients (79.66\%) and the non-dominant side was affected in 12 patients (20.34\%). The mean time of preoperative pain was 36 months (2 to 180 months).

The tears were diagnosed through physical examination, radiography and magnetic resonance imaging (MRI). (Figure 1) The study was authorized by the Ethics Committee on Research of Faculdade de Medicina do ABC under number 357/2009. All patients in the study signed an informed consent form.

In the preoperative period, the patients were evaluated for range of motion - elevation, lateral rotation to the side of the body, using a goniometer and medial rotation based on the vertebral level. They were also evaluated by the Functional Scale of the University of California, Los Angeles (UCLA). Besides, the tests of Neer, Hawkins, Yokum, Jobe, lift-off, abdominal grip, Cancela and Patte, Speed, O'Brien and Yergason were performed.

The surgeries were performed in the beach chair position, with arthroscopic repair of the tears with metal or bioabsorbable anchors. Mean postoperative follow-up time was 18.88 months (12 to 57 months). In the latter evaluation, the patients were examined by evaluators who were unaware of their pre and intraoperative data. Statistical analysis was performed by comparing the pre and postoperative results of elevation, medial rotation, lateral rotation and the UCLA scale score using the Wilcoxon signed-rank test, with a significance level of $5 \%(p<0.05)$. The Mann-Whitney test was used to evaluate the relationship between the type of subscapular tear and its association with the postoperative functional result by the UCLA scale. The Spearman rank correlation coefficient was used to study the relationship between time of preoperative pain and postoperative functional result by the UCLA scale.

\section{RESULTS}

\section{Pre-operative evaluation}

With regard to range of motion, the elevation ranged from $85^{\circ}$ to $160^{\circ}$ (mean of $135^{\circ}$ ). Medial rotation ranged from T5 to gluteus (mean at L1). Lateral rotation ranged from $10^{\circ}$ to $80^{\circ}$ (mean of $46^{\circ}$ ). The UCLA functional scale score ranged from 8 to 25 points (mean of 18.2 points).

In $50 \%$ of the cases, physical examination was not able to confirm subscapularis tear and $70 \%$ of the patients presented pain or positive maneuvers for biceps tear.

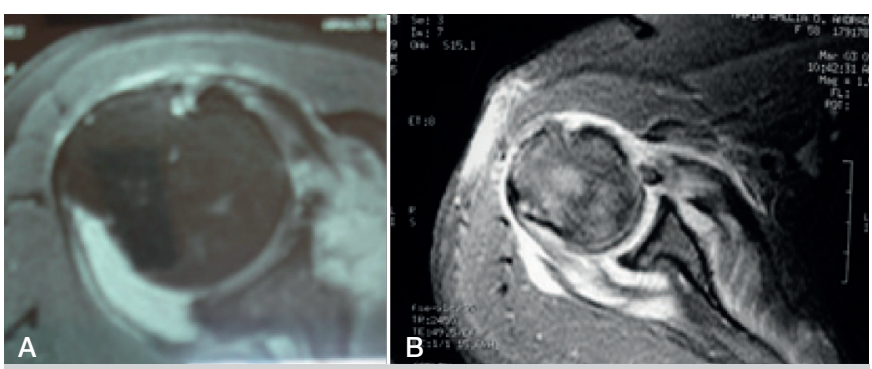

Figure 1. A and B. Magnetic resonance imaging of the shoulder (axial section) showing, in both cases, subscapular tear and dislocation of the long head of biceps

\section{Intraoperative evaluation}

The number of anchors to repair the tears ranged from one to five, and in 15 cases, tendon-to-tendon stitches were required. (Figures 2-A and 2-B). The following were performed: 40 tenotomies and six biceps tenodeses (Figures 3-A and 3-B). Of the patients presenting acromion-clavicular pain, all were submitted to the mini-Munford procedure. Of the 59 cases, 44 had partial subscapular tendon tears and 15 had total subscapular tendon tears.

\section{Pre-operative evaluation}

As for the range of motion, the mean final elevation was $158^{\circ}\left(100^{\circ}\right.$ to $180^{\circ}$ ). In the final medial rotation, the patients were able to reach mean T10, minimum gluteal region and maximum T5. The mean final lateral rotation was $58^{\circ}\left(0^{\circ}\right.$ to $\left.90^{\circ}\right)$.

Regarding elevation, there was a mean improvement of $23^{\circ}$ $(p<0.001)$. As for medial rotation, a mean gain of three vertebral levels was found $(p<0.001)$. In lateral rotation, there was a mean improvement of $12^{\circ}(p<0.001)$. (Table 1$)$

The mean UCLA functional scale score in the postoperative period was 30.71 points (minimum 17 and maximum 35). Therefore, a mean increase of 12.52 points was found $(p<0.001)$. (Table 1$)$ Twenty-three

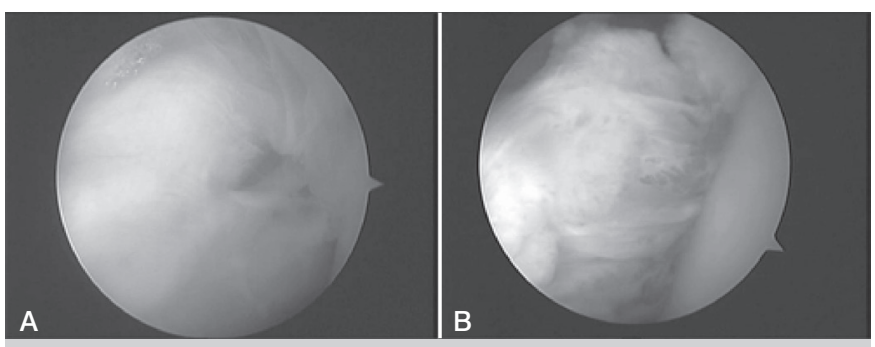

Figure 2. A) Subscapular tendon tear. B) Repair.

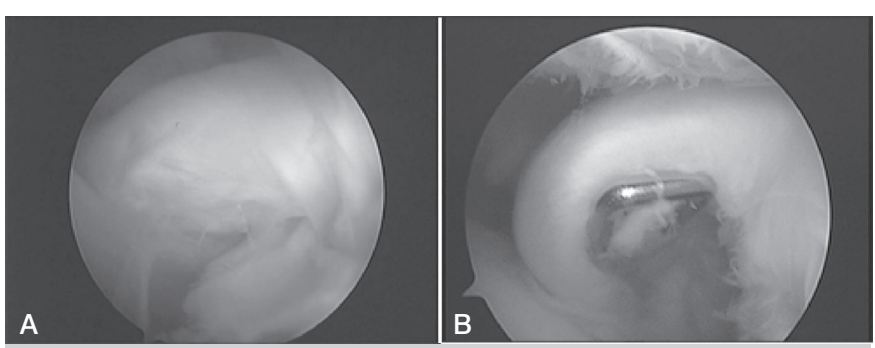

Figure 3. A) Long head of biceps tear and B) tenotomy.

Table 1. Wilcoxon signed-rank test results.

\begin{tabular}{|c|c|c|c|c|c|c|}
\hline Pair of variables & $N$ & Mean & \begin{tabular}{|l|} 
Standard \\
deviation
\end{tabular} & Minimum & Maximum & $\begin{array}{c}\text { Significance } \\
(p)\end{array}$ \\
\hline $\begin{array}{l}\text { Pre-operative } \\
\text { evaluation }\end{array}$ & 59 & 135 & 23.46 & 80 & 160 & \multirow{2}{*}{$<0.001$} \\
\hline $\begin{array}{c}\text { Pre-operative } \\
\text { evaluation }\end{array}$ & 59 & 158 & 13.43 & 100 & 180 & \\
\hline $\begin{array}{c}\text { Pre-operative } \\
\text { external rotation }\end{array}$ & 59 & 46 & 14.37 & 10 & 80 & \multirow{2}{*}{$<0.001$} \\
\hline $\begin{array}{l}\text { Post-operative } \\
\text { external rotation }\end{array}$ & 59 & 58 & 14.57 & 0 & 90 & \\
\hline $\begin{array}{c}\text { Pre-operative } \\
\text { internal rotation }\end{array}$ & 59 & 5.73 & 3.81 & 0 & 13 & \multirow{2}{*}{$<0.001$} \\
\hline $\begin{array}{l}\text { Post-operative } \\
\text { internal rotation }\end{array}$ & 59 & 8.44 & 3.97 & 0 & 13 & \\
\hline Pre-operative UCLA & 59 & 18.19 & 4.17 & 8 & 25 & \multirow{2}{*}{$<0.001$} \\
\hline Post-operative UCLA & 59 & 30.7 & 4.89 & 17 & 35 & \\
\hline
\end{tabular}

Source: SAME, FMABC. 
cases (39\%) were classified as excellent results, twenty (33.9\%) as good, fourteen (23.7\%) as regular and two cases (3.4\%) as bad. Comparing the 44 cases with partial subscapular tendon tears and the 15 cases of total tears, we found that the mean UCLA functional scale in the postoperative period were 31.70 and 27.80 , respectively $(p<0.035)$. (Table 2) By evaluating only those cases with total subscapular tear, we found statistically significant improvement after surgery $(p=0.002)$. (Table 3$)$

Regarding the preoperative pain time, whose mean was 35.59 months (minimum 2 months and maximum 180 months), a statistically significant relationship was found with the postoperative functional UCLA outcome $(p=0.001$ and $r=-0.423)$. (Table 4$)$

We also found five complications (8.5\%): four rotator cuff re-ruptures and one case of adhesive capsulitis. The re-ruptures were diagnosed when we performed magnetic resonance imaging in five patients with persistent pain for more than 6 months postoperatively.

\section{DISCUSSION}

The term "anterior superior tears" was introduced by Warner et $\mathrm{al}^{1}$ to describe associated lesions of the subscapular and supraspinal tendons. This type of tear occurs less frequently than the associated supraspinatus and infraspinatus tears and may be underdiagnosed. ${ }^{2}$ Information on the surgical treatment of subscapular tear associated with supraspinatus tear is limited., ${ }^{1,3}$

Warner et al. report that only $4 \%$ of their cases of rotator cuff tears were anterior posterior tears. ${ }^{1}$ Frankle and Cofield presented in 24 cases of anterior posterior tears out of 301 cases of rotator cuff tears. ${ }^{4}$ Bigliani et al. described the results of 61 cases of lesions of at least two rotator cuff tendons, of which only 11 were anterior posterior tears. ${ }^{5}$ Geber et al. presented an incidence of $5.5 \%$ of subscapular tears isolated or associated with supraspinatus tears. ${ }^{3}$ In our study, these tears represented only $5.6 \%$ of rotator cuff tears. Regarding etiology, a potential cause of subscapular and supraspinatus tendon tear would be trauma to the affected shoulder on lateral rotation and abduction. ${ }^{4}$ In our study, $35 \%$ of the tears were of traumatic origin. Another potential etiology would be impact with coracoid process caused by reduced space between the coracoid process and the minor tubercle, with normal values ranging from 9 $\mathrm{mm}$ to $11 \mathrm{~mm}$, although some authors believe that this decreased coracoid-humerus space is a consequence of the rotator cuff tear, not the cause. ${ }^{4,5}$

Subluxations of the long head of the biceps tendon (LBT) may be one of the possible causes of partial subscapular tears, as well as subscapular tendon overload after supraspinatus tear. ${ }^{6}$ The association of some degree of LBT injury is commonly found in rotator interval tears, ${ }^{2,6}$. However, it is still unknown whether cuff tears cause any LBT tears or vice versa. ${ }^{3}$ According to Habermeyer et al., biceps pulley tears may be caused by degeneration or trauma. According to this author, pulley tears can also be caused when the
Table 4. Spearman's correlation results.

\begin{tabular}{c|c|c}
\hline Variable & Statistics & Time of Pain (months) \\
\hline \multirow{2}{*}{ PO UCLA } & Coefficient of Correlation $(r)$ & -0.423 \\
\cline { 2 - 3 } & Sig. $(p)$ & 0.001 \\
\hline & $n$ & 59 \\
\hline
\end{tabular}

\section{SOURCE: SAME, FMABC.}

pitching movement is abruptly stopped. ${ }^{7}$ Gerber was the first one to describe the anterior posterior impact that may cause LBT pulley and subscapular tear. ${ }^{8}$ In our study, in $78 \%$ of the cases, LBT tear was confirmed on surgery.

In his study, Bennett reports that 18 of 19 patients had biceps tears. ${ }^{2}$ LBT subluxation caused by biceps pulley tear generates loss of anterior humeral head stability over the glenoid which, associated with biceps subluxation, is the initial event of anterior posterior impact. $^{9}$

Isolated or combined subscapular tendon tears can be difficult to diagnose. In cases of total tears, physical examination detects the tear, as well as MRI., ${ }^{4,5}$ Lesions of the uppermost portion of this tendon represent a problem. Physical examination is often incapable of detecting the tear and MRI is difficult to interpret. ${ }^{1,5}$ In our study, we found that in $50 \%$ of the cases, physical examination was not able to detect subscapular tendon tear. These patients did not present any increase in lateral rotation and the lift-off and abdominal-press tests were negative. In addition, MRI was not conclusive for tendon tears. During surgery, high subscapular tears were observed, most of which involved the LBT pulley.

Burkhart ${ }^{10}$ reports that isolated supraspinatus or associated tears may function as if biomechanically and functionally intact, but associated supraspinatus and subscapular tears alter normal shoulder kinematics. Several authors have described that the superior portion of the subscapular tendon insertion is the most important portion, with 14 to $16 \mathrm{~mm}$ of thickness in general. ${ }^{11-13}$ Therefore, in our opinion, it is important to redo this insertion to restore the shoulder mechanics, even when we encounter partial tears.

In the analysis of Gerber et al. outcomes from 56 cases of anterior superior tears, worse functional results were found compared to that of the posterior-superior rotator cuff tears. ${ }^{14}$ Frankle and Cofield reported that postoperative elevation was, on average, 134 degrees, but $25 \%$ of patients had significant weakness and pain. ${ }^{4}$ Warner et al. reported similar results to those of the European experience. ${ }^{1}$ In our study, the mean interval between onset of symptoms and surgery was 36 months, with four cases of rotator cuff re-ruptures, representing $6.8 \%$ of the total cases operated and $75 \%$ of the complications. Two of the cases had a time interval between the onset of symptoms and surgery of 12 months and two of 24 months. We evaluated whether there was any relationship between the time of preoperative pain and the functional results analyzed by the UCLA functional scale and found a statistically significant relationship.

Table 2. Mann-Whitney Test Results.

\begin{tabular}{c|c|c|c|c|c|c|c|c|c}
\hline Sub tear & $\mathbf{n}$ & Mean & Standard deviation & Minimum & Maximum & 25 percentile & Median & 75 percentile & Sig. (p) \\
\hline partial & 44 & 31.70 & 3.86 & 23.00 & 35.00 & 29.00 & 33.00 & 35.00 & \multirow{2}{*}{0.035} \\
\hline total & 15 & 27.80 & 6.43 & 17.00 & 35.00 & 22.00 & 31.00 & 35.00 & \\
\hline Total & 59 & 30.71 & 4.89 & 17.00 & 35.00 & 28.00 & 33.00 & 35.00 & \\
\hline
\end{tabular}

Source: SAME, FMABC

Table 3. Wilcoxon signed-rank test results.

\begin{tabular}{c|c|c|c|c|c|c|c|c|c}
\hline Pair of variables & $\mathbf{n}$ & Mean & Standard deviation & Minimum & Maximum & 25 percentile & Median & 75 percentile & Sig. ( $\mathbf{p}$ ) \\
\hline PRE UCLA & 15 & 18.47 & 3.46 & 12.00 & 25.00 & 17.00 & 18.00 & 21.00 \\
\hline POST UCLA & 15 & 27.80 & 6.43 & 17.00 & 35.00 & 22.00 & 31.00 & 35.00 & 0.002 \\
\hline
\end{tabular}

Source: SAME, FMABC 
According to a few reports of arthroscopic treatment, this technique allegedly has important advantages over open repair, since it requires using the deltopeitoral route and a bigger extension to mobilize and repair the supraspinatus tendon, ${ }^{5}$ which leads to many more adhesions and fibrosis and impairs rehabilitation. Bennett et al. reports that arthroscopic treatment of anterior posterior lesions provides improved internal rotation and pain relief, and patients return to functional activities more rapidly. In their study, Ide et al. ${ }^{15}$ reported that 13 of 20 patients with a minimum follow-up of two years had an intact repair. Similarly, Burkhart and Tehrany ${ }^{16}$ report good or excellent results in 23 of 25 patients who underwent arthroscopic vision repair of subscapular tear associated with supraspinatus tear. In our study, there was statistical significance improvement of all parameters analyzed. In our opinion, this fact is mainly due to the type of arthroscopic vision repair and proper treatment of the high subscapular tears, which were the majority. Even in the cases of total subscapular tear, there was a significant improvement (mean of 27.80 points). However, comparing the outcomes of patients whose subscapular tears were partial tears with cases of total tears, we found a statistically superior outcomes $(p<0.035)$ in cases of partial tears.

\section{CONCLUSION}

Treatment with arthroscopic vision for the repair of anterior superior tears produced satisfactory results (72.9\%), 39\% of which were classified as excellent and $33.9 \%$ were classified as good, with improved range of motion and UCLA functional scale, in addition to low rates of complications.

AUTHORS' CONTRIBUTIONS: Each author contributed individually and significantly to the development of the manuscript. RI (0000-0001-7718-1186)*: revision; JM (0000-0003-1812-8566)*: patient operations and writing, LGPN (0000-0002-1302-2570)*: surgery and revision; LHOA (0000-0003-1247-971X)*: data evaluation and patient operations; RSB (0000-0003-4672-0380)*: data analysis and operations; GHVL (0000-0003-4897-7657)*: operations and data collection. *ORCID (Open Researcher and Contributor ID).

\section{REFERENCES}

1. Warner JJ, Higgins L, Parsons IM 4th, Dowdy P. Diagnosis and treatment of anterosuperior rotator cuff tears. J Shoulder Elbow Surg. 2001;10(1):37-46.

2. Bennett WF. Arthroscopic repair of anterosuperior (supraspinatus/subscapularis) rotator cuff tears: a prospective cohort with 2- to 4-year follow-up. Classification of biceps subluxation/instability. Arthroscopic. 2003;19(1):21-33.

3. Gerber C, Fuchs B, Hodler J. The results of repair of massive tears of the rotator cuff. J Bone Joint Surg Am. 2000;82(4):505-15.

4. Frankle MA, Cofield $\mathrm{RH}$. Rotator cuff tears including the subscapularis. In: Proceedings of the Fifth International Conference on Surgery of the Shoulder. Paris, France: International Shoulder and Elbow Society; 1992:52.

5. Bigliani LU, Cordasco FA, Mcllveen SJ, Musso ES. Operative repairs of massive rotator cuff tears: long-term results. J Shoulder Elbow Surg. 1992; 1(3):120-30.

6. Sakurai G, Ozaki J, Tomita Y, Kondo T, Tamai S. Incomplete tears of the subscapularis tendon associated with tears of the supraspinatus tendon: cadaveric and clinical studies. J Shoulder Elbow Surg. 1998;7(5):510-5.

7. Habermeyer P, Magosch P, Pritsch M, Scheibel MT, Lichtenberg S. Anterosuperior impingement of the shoulder as a result of pulley lesions: A prospective arthroscopic study. J Shoulder Elbow Surg. 2004;13(1):5-12.

8. Gerber C, Krushell RJ. Isolated rupture of the tendon of the subscapularis muscle: clinical features in 16 cases. J Bone Joint Surg Br. 1991;73(3):389-94

9. Gartsman GM. Massive, irreparable tears of the rotator cuff: results of operative debridement and subacromial descompression. J Bone Joint Surg Am. 1997;79(5):715-21.

10. Burkhart SS. Reconciling the paradox of rotator cuff repair versus debridement: A unified biomechanical rationale for the treatment of rotator cuff tears. Arthroscopy. 1994;10(1):4-19.

11. Halder AM, O'Driscoll SW, Heers G, Mura N, Zobitz ME, An KN, et al. Biomechanical comparison of effects of supraspinatus tendon detachments, tendon defects, and muscle retractions. J Bone Joint Surg Am. 2002;84-A(5):780-5.

12. Ide J, Tokiyoshi A, Hirose J, Mizuta HJ. An anatomic study of the subscapularis insertion to the humerous: the subscapularis footprint. Arthroscopic. 2008;24(7):749-53.

13. Curtis AS, Burbank KM, Tierney JJ, Scheller AD, Curran AR. The insertional footprint of the rotator cuff: an anatomic study. Arthroscopic. 2006;22(6):603-9.

14. Gerber $C$, Rippstein R. Combined lesions of the subscapularis and supraspinatus tendons: a multi-center analysis of 56 cases. Proceedings of the Fifth International Conference on Surgery of the Shoulder. Paris, France: International Shoulder and Elbow Society; 1992:51.

15. Ide J, Tokiyoshi A, Hirose J, Mizuta H. Arthroscopic repair of traumatic combined rotator cuff tears involving the subscapularis tendon. J Bone Joint Surg Am. 2007;89(11):2378-88

16. Burkhart SS, Tehrany AM. Arthroscopic subscapularis tendon repair: Technique and preliminary results. Arthroscopy. 2002;18(5):454-63. 